\title{
Thrombomodulin Ala455Val Polymorphism and the risk of cerebral infarction in a biracial population: the Stroke Prevention in Young Women Study
}

\author{
John W Cole*1,2,4, Stacy C Roberts ${ }^{5}$, Margaret Gallagher ${ }^{5}$, Wayne H Giles ${ }^{6}$, \\ Braxton D Mitchell ${ }^{2,3}$, Karen K Steinberg7, Marcella A Wozniak ${ }^{1}$, \\ Richard F Macko ${ }^{1,4}$, Laurie J Reinhart ${ }^{3}$ and Steven J Kittner ${ }^{1,2,4}$
}

\begin{abstract}
Address: ${ }^{1}$ Department of Neurology, University of Maryland School of Medicine, Baltimore, Maryland, USA, ${ }^{2}$ Epidemiology and Preventive Medicine, University of Maryland School of Medicine, Baltimore, Maryland, USA, ${ }^{3}$ Department of Medicine University of Maryland School of Medicine, Baltimore, Maryland, USA, ${ }^{4}$ Geriatrics Research, Education, and Clinical Center, Department of Veterans Affairs Medical Center, Baltimore, Maryland, USA, ${ }^{5}$ Molecular Biology Branch, National Center for Environmental Health, Centers for Disease Control and Prevention, Atlanta, Georgia, USA, ${ }^{6}$ Division of Adult and Community Health, National Center for Chronic Disease Prevention and Health Promotion, Centers for Disease Control and Prevention, Atlanta, Georgia, USA and ${ }^{7}$ Coordinating Center for Health Promotion, Centers for Disease Control and Prevention, Atlanta, Georgia, USA

Email: John W Cole* - jcole@som.umaryland.edu; Stacy C Roberts - MXG2@CDC.GOV; Margaret Gallagher - MXG2@CDC.GOV; Wayne H Giles - hwg0@cdc.gov; Braxton D Mitchell - bmitchel@medicine.umaryland.edu; Karen K Steinberg - kks1@cdc.gov; Marcella A Wozniak - mwozniak@som.umaryland.edu; Richard F Macko - rmacko@grecc.umaryland.edu; Laurie J Reinhart - Ireinhar@medicine.umaryland.edu; Steven J Kittner - skittner@som.umaryland.edu

* Corresponding author
\end{abstract}

Published: 0 I December 2004

BMC Neurology 2004, 4:21 doi:10.1 I86/I47|-2377-4-2I
Received: 12 July 2004

Accepted: 0 I December 2004

This article is available from: http://www.biomedcentral.com/I47I-2377/4/2I

(c) 2004 Cole et al; licensee BioMed Central Ltd.

This is an Open Access article distributed under the terms of the Creative Commons Attribution License (http://creativecommons.org/licenses/by/2.0), which permits unrestricted use, distribution, and reproduction in any medium, provided the original work is properly cited.

\begin{abstract}
Background: The genes encoding proteins in the thrombomodulin-protein $C$ pathway are promising candidate genes for stroke susceptibility because of their importance in thrombosis regulation and inflammatory response. Several published studies have shown that the Ala455Val thrombomodulin polymorphism is associated with ischemic heart disease, but none has examined the association with stroke. Using data from the Stroke Prevention in Young Women Study, we sought to determine the association between the Ala455Val thrombomodulin polymorphism and the occurrence of ischemic stroke in young women.
\end{abstract}

Methods: All 59 hospitals in the greater Baltimore-Washington area participated in a populationbased case-control study of stroke in young women. We compared I4I cases of first ischemic stroke ( $44 \%$ black) among women 15 to 44 years of age with 210 control subjects ( $35 \%$ black) who were identified by random digit dialing and frequency matched to the cases by age and geographical region of residence. Data on historical risk factors were collected by standardized interview. Genotyping of the thrombomodulin Ala455Val polymorphism was performed by pyrosequencing.

Results: The $A$ allele (frequency $=0.85$ ) was associated with stroke under the recessive model. After adjustment for age, race, cigarette smoking, hypertension, and diabetes, the AA genotype, compared with the $A V$ and $V V$ genotypes combined, was significantly associated with stroke (odds ratio $1.9,95 \% \mathrm{Cl}$ I.I-3.3). The AA genotype was more common among black than white control subjects $(81 \%$ versus $68 \%$ ) but there was no significant interaction between the risk genotype and race (adjusted odds ratio 2.7 for blacks and 1.6 for whites). A secondary analysis removing all 
probable $(n=16)$ and possible $(n=15)$ cardioembolic strokes demonstrated an increased association (odds ratio $2.2,95 \% \mathrm{Cl}$ I.2-4.2).

Conclusions: Among women aged 15 to 44 years, the AA genotype is more prevalent among blacks than whites and is associated with increased risk of early onset ischemic stroke. Removing strokes potentially related to cardioembolic phenomena increased this association. Further studies are needed to determine whether this polymorphism is functionally related to thrombomodulin expression or whether the association is due to population stratification or linkage to a nearby functional polymorphism.

\section{Background}

Thrombosis is a dynamic balance between factors that promote clot formation, antithrombotic mechanisms, and fibrinolysis. Central to this balance is the thrombomodulin-protein $\mathrm{C}$ antithrombotic mechanism. Thrombomodulin forms a 1:1 complex with thrombin on the vascular endothelium, thereby inhibiting the procoagulant actions of thrombin and converting protein $\mathrm{C}$ to activated protein $\mathrm{C}$ [1]. Activated protein $\mathrm{C}$ promotes fibrinolysis, inhibits thrombosis by inactivating clotting factors Va and VIIIa, and reduces inflammation by decreasing white blood cell and nuclear factor kappa-B activation [2-5]. These relationships are demonstrated in Figure 1. Because of the central role that the thrombomodulin-protein $\mathrm{C}$ pathway plays in thrombosis regulation and inflammatory response, the genes encoding these pathway proteins are promising candidate genes regarding stroke susceptibility.

The thrombomodulin gene (THBD) maps to chromosome 20p11.2, contains a single exon and no introns, and spans 4 kb (OMIM 188040, UniGene NM_000361, Locus Link 7056). The thrombomodulin protein is expressed primarily on the luminal surface of vascular endothelial cells and consists of 557 amino acids (aa) (60,300 Dalton): an N-terminal lectin-like module (aa 1-154), a hydrophobic region (aa 155-222), six epidermal growth factor (EGF)-like modules (aa 223-462), a serine and threonine rich region (aa 463-497), a single transmembrane segment (aa 498-521), and a short cytoplasmic tail (aa 522-557) [6]. A single nucleotide polymorphism $(\mathrm{C} \rightarrow \mathrm{T})$ at position $+1418(\mathrm{C} 1418 \mathrm{~T})$ encodes for an aa change from alanine to valine at protein position 455 (Ala455Val) [7]. The location of this aa variation corresponds to the sixth EGF region of the thrombomodulin protein as seen in Figure 2. This location has been shown to be responsible for the high-affinity binding of thrombin and for the suspension of thrombin at a specific position above the endothelial surface in relation to other cofactors, thereby producing optimal protein $\mathrm{C}$ activation by thrombin $[2,8]$.

A few studies have shown that the THBD Ala455Val polymorphism is associated with ischemic heart disease

\section{Thrombomodulin (TM) Function: Membrane Bound}

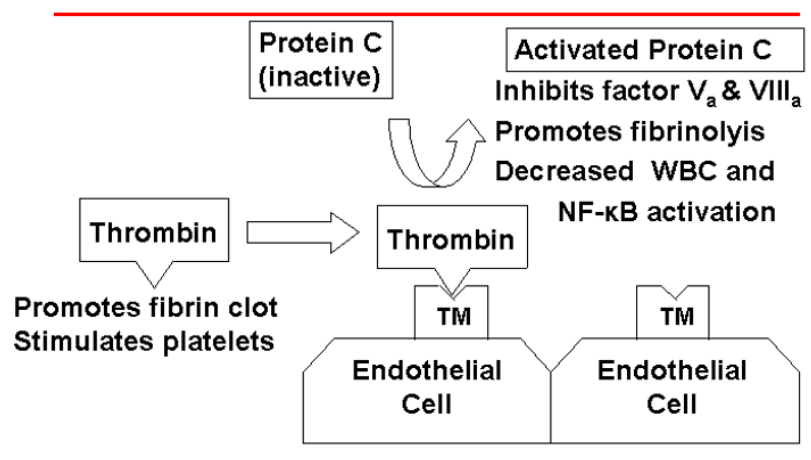

Figure I

Thrombomodulin / Protein-C relationships and function

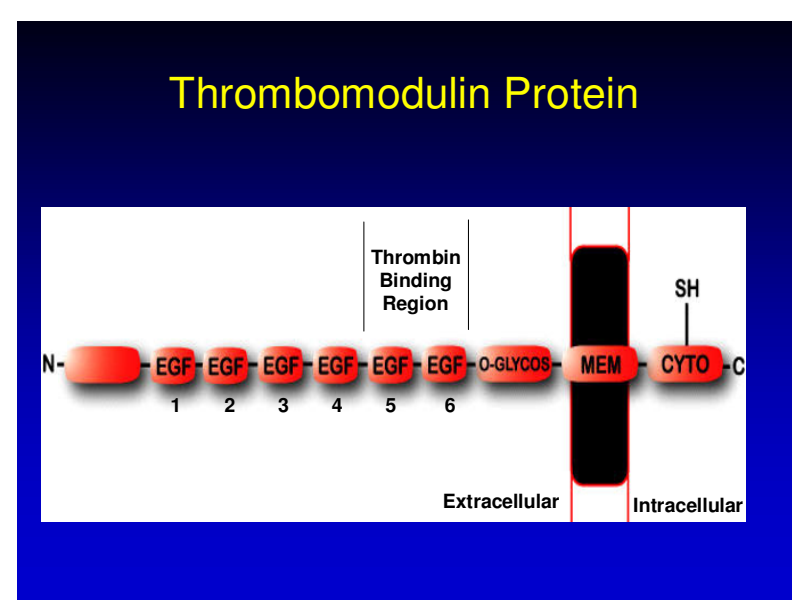

Figure 2

Thrombomodulin protein 
$[9,10]$, but we know of no prior reports examining this polymorphism's association with stroke. Using data from the Stroke Prevention in Young Women Study [11], we sought to determine the association between the THBD Ala455Val polymorphism and the occurrence of ischemic stroke in young women. In addition, because cardioembolic stroke has a lesser degree of familial aggregation [12], we performed a secondary analysis excluding cases with cardioembolic etiologies.

\section{Methods}

The Stroke Prevention in Young Women Study (SPYW) is a population-based case-control study that was initiated to examine risk factors for ischemic stroke in young women. In that study the term "population-based" means that cases and their comparison group were identified from the same defined population. The study area included all of Maryland (except the far Western panhandle), Washington DC, and the southern portions of both Pennsylvania and Delaware. Cases were female patients 15 to 44 years of age with a first cerebral infarction as identified by discharge surveillance at 59 regional hospitals and through direct referral by regional neurologists. The methods for discharge surveillance, chart abstraction, and case adjudication have been described previously $[11,13,14]$. The adjudication of stroke cases was performed blinded to genetic information. Stroke cases were classified as having a probable, possible or undetermined etiology as per prior description $[13,14]$. Control subjects were women without a history of stroke. They were identified by random digit dialing and were frequency matched to the cases by age and geographic region of residence. The original SPYW study consisted of 227 cases and 342 controls. DNA samples were available for a subset of this population consisting of 141 cases and 210 controls.

We performed THBD genotyping at the Ala455Val polymorphism for 141 cases and 210 control subjects. This included all case and control samples that were available at that time. Genotyping was performed blinded to casecontrol status. Genomic DNA was extracted from stored peripheral blood lymphocytes by using standard protocols (Gentra Systems, Minneapolis, MN). The THBD Ala455Val polymorphism was determined by pyrosequencing. The single-nucleotide polymorphism region of the gene was amplified by polymerase chain reaction (PCR) with the use of published primers [10] except that we labeled the reverse primer with biotin. PCR was performed in $40 \mu \mathrm{l}$ reactions containing $40 \mathrm{ng}$ of genomic DNA, 15 pmol each of forward and reverse primer, $1.5 \mathrm{U}$ of Amplitaq (Applied Biosystems, Foster City, CA) and MasterAmp PCR PreMix D (Epicenter, Madison, WI). The resulting biotinylated PCR product was bound to streptavidin-coated Sepharose HP beads (Amersham Pharmacia
Biotech, Uppsala, Sweden) and the product was denatured according to the manufacturer's protocol (PSQ 96 Sample Preparation Kit, Pyrosequencing AB, Uppsala, Sweden). Following denaturation, an internal sequencing primer (5'-CGACTCGGC CCT T-3') was annealed to the bound single-stranded DNA. We used an automated pyrosequencing instrument (PSQ96, Pyrosequencing AB, Uppsala, Sweden) to perform the genotyping $[15,16]$. The reactions were performed at $28^{\circ} \mathrm{C}$ and contained the bound single-stranded DNA with annealed sequencing primer, enzymes (DNA polymerase, apyrase, luciferase, and activating transcription factor sulfurylase), nucleotides (dTTP, dGTP, dCTP, or dATP $\alpha$ S), and substrate (luciferin) supplied by the manufacturer. We monitored continuously the output from the charge-coupled device as a pyrogram, and we analyzed manually the results from the completed sequencing reactions by visually inspecting each program. The validity of the method was confirmed by fluorescent dye terminator sequencing of a subset of samples using standard protocols on an ABI 3100 genetic analyzer (Applied Biosystems, Foster City, CA).

We assessed the following potential confounders of the association between the alleles of the THBD Ala455Val polymorphism and stroke: age, race, current cigarette smoking, hypertension, diabetes mellitus, history of angina or myocardial infarction (angina/MI), use of oral contraceptive pills (OCP) or hormone replacement therapy (HRT), sickle cell disease, and sickle cell trait. Age, race, current cigarette smoking status, use of OCP or HRT was determined by subject reports (or proxy report, if a participant was unable to answer). Hypertension and diabetes mellitus, sickle cell disease or sickle cell trait were determined by asking study participants (or a proxy) if a physician had ever told them that they had the condition.

We compared means by $\mathrm{t}$ tests and proportions by $\chi 2$ tests. The probability values presented are based on twosided tests. Because of the low frequency of the V455 allele, we compared the frequency of the combined AV/VV genotype between cases and controls. Adjusted odds ratios derived from logistic regression were used to determine whether the presence of the Ala455Val test allele was associated with an increased risk for stroke after differences in age, race, current cigarette smoking, hypertension, and diabetes mellitus were controlled for. Additional analyses included: 1). adding ischemic heart disease (angina/MI) into the logistic regression model; 2 ). evaluation for interactions between genotype and $\mathrm{OCP} /$ HRT 3). an analysis excluding sickle cell trait, and 4). an analysis excluding cardioembolic strokes. 
Table I: Characteristics, by case-control status

\begin{tabular}{llll}
\hline & Case $(\mathrm{N}=14 \mathrm{I})$ & Control $(\mathrm{N}=2 \mathrm{I} 0)$ & $\mathrm{P}$-value \\
\hline Mean age (years) & 35.5 & 36.1 & $.3 \mathrm{I}$ \\
Black (\%) & 44.0 & 34.8 & .12 \\
Current Smokers (\%) & 45.4 & 26.7 & $<.00 \mathrm{I}$ \\
Hypertension (\%) & 27.7 & 13.3 & $<.0 \mathrm{I}$ \\
Diabetes mellitus (\%) & 13.5 & 3.3 & $<.00 \mathrm{I}$ \\
Angina/MI (\%) & 14.9 & 4.3 & $<.00 \mathrm{I}$ \\
& & &
\end{tabular}

Table 2: Characteristics among control subjects, by thrombomodulin genotype status

\begin{tabular}{llll}
\hline & AA (n= I52) & AV/VV (n= 58) & p-value \\
\hline Mean age (years) & 36.5 & 34.9 & 0.17 \\
Black (\%) & 38.8 & 24.1 & $<.05$ \\
Current Smokers (\%) & 26.3 & 27.6 & 0.86 \\
Hypertension (\%) & 11.2 & 19.0 & 0.18 \\
Diabetes Mellitus (\%) & 4.0 & 1.7 & 0.34 \\
Angina/MI (\%) & 2.4 & 1.9 & 0.26 \\
\hline
\end{tabular}

\section{Results}

\section{Subject characteristics}

Characteristics by case-control status are described in Table 1 . The mean age of the cases (i.e., women with a first cerebral infarction) was 35.5 years and the mean age of control subjects was 36.1 years. Cases were more likely than control subjects to be black (44.0\% versus $34.8 \%$, p $=0.12$ ), and were significantly more likely to currently smoke cigarettes $(\mathrm{p}<0.001)$, to have hypertension ( $\mathrm{p}<$ $0.01)$, diabetes $(\mathrm{p}<0.001)$ and history of angina/MI ( $\mathrm{p}<$ $0.001)$. No study subjects reported sickle cell disease, however 6 cases and 5 controls reported sickle cell trait (non-significant difference). Twenty cases and 34 controls reported use of oral contraceptive pills (OCP) or hormone replacement therapy (non-significant difference).

\section{Genotype and vascular risk factor distributions}

The distribution of genotypes was in Hardy Weinberg equilibrium for the pooled set of cases and controls, both in total and by race.

Among control subjects, the prevalence of the AA genotype was $81 \%$ (59/73) for blacks and 68\% (93/137) for whites. The relationship between the Ala455Val genotypes and selected stroke risk factors in control subjects is summarized in Table 2. Blacks were significantly more likely to have the AA genotype than the AV and VV genotypes combined (38.8\% vs. $24.1 \%$, p < 0.05). In contrast, there were no significant differences in prevalence of hypertension, diabetes, angina/MI, or sickle cell trait between carriers and non-carriers of the $\mathrm{V}$ allele, nor did the frequency of cigarette smoking or OCP/HRT use differ significantly between the two groups.

\section{Genotype risk}

Table 3 shows the association of the AA genotype with stroke, stratified by race and other vascular risk factors. The association between the AA genotype and stroke was 2.7 (95\% CI 0.9-8.0) among blacks and 1.6 (95\% CI 0.83.2) among whites. Since logistic regression analysis did not show a significant interaction by race (i.e., the effect of the AA genotype did not differ significantly between blacks and whites), subsequent analyses were conducted on the combined sample. After adjustment for age, race, cigarette smoking, hypertension, and diabetes, the AA genotype was found to be significantly associated with stroke compared with the AV and VV genotypes (OR 1.9, 95\% CI 1.1-3.3).

The strength of association between the AA genotype and stroke remained unchanged including history of angina or myocardial infarction in the logistic regression model (OR 1.9, 95\% CI 1.1-3.3). Neither OCP/HRT use, nor sickle cell trait demonstrated an interaction with genotype and additional adjustment for these factors did not alter the association between the AA genotype and stroke.

\section{Stroke subtype}

Among the 141 stroke patients, 70 (50\%) had a least 1 probable cause, $30(21 \%)$ had no probable cause but a least one possible cause, and 41 (29\%) were indeterminate. Table 4 shows the distribution of probable and possible causes. "Other determined causes" of stroke included hematologic disorders, nonatherosclerotic vasculopathy (eg, vasculitis and dissection), migraine, drug abuse and stroke associated with oral contraceptive or exogenous estrogen use.

A secondary analysis removing all probable $(n=16)$ or possible $(\mathrm{n}=15)$ cardioembolic strokes was performed using the same adjusted model including age, race, smoking, hypertension, and diabetes. An increased association between non-cardioembolic stroke and the AA genotype was demonstrated (odds ratio 2.2, 95\% CI 1.2-4.2).

\section{Discussion}

In our study of the THBD Ala455Val polymorphism, the prevalence of the AA genotype among our control population was similar to that previously reported for the Atherosclerosis Risk in Communities (ARIC) Study population [10]. Our results indicate a positive association between the AA genotype and stroke among women aged 15 to 44 years. Furthermore, an increased association was 
Table 3: Frequency of the THBD Ala455Val AA genotype in cases and controls (proportion with AA genotype in parentheses) as stratified by race and other stroke risk factors; with associated crude and adjusted odds ratios

\begin{tabular}{lllll}
\hline Risk Factor & $\begin{array}{l}\text { Percentage of cases with } \\
\text { the AA genotype } \\
\text { (proportion) }\end{array}$ & $\begin{array}{l}\text { Percentage of Controls } \\
\text { with the AA genotype } \\
\text { (proportion) }\end{array}$ & Crude OR ^ (95\% Cl) & Adjusted OR*^ (95\% Cl) \\
\hline White & $79 \%(62 / 79)$ & $68 \%(93 / 137)$ & $1.7(0.9-3.3)$ & $1.6(0.8-3.2)$ \\
Black & $87 \%(54 / 62)$ & $81 \%(59 / 73)$ & $1.8(0.4-7.9)$ & $2.7(0.9-8.0)$ \\
Current smoking & $84 \%(54 / 64)$ & $71 \%(40 / 56)$ & $2.2(0.9-5.3)$ & $3.0(1.1-7.8)$ \\
No current smoking & $81 \%(62 / 77)$ & $73 \%(112 / 154)$ & $1.6(0.8-3.0)$ & $1.5(0.7-2.9)$ \\
Hypertension & $85 \%(33 / 39)$ & $61 \%(17 / 28)$ & $3.6(1.1-11.3)$ & $1.4-22.6)$ \\
No hypertension & $81 \%(83 / 102)$ & $74 \%(135 / 182)$ & $1.5(0.8-2.8)$ & Not performed \\
Diabetes** & $84 \%(16 / 19)$ & $86 \%(6 / 7)$ & $1.8(1.0-3.1)$ & $1.9(1.1-3.4)$ \\
No Diabetes & $82 \%(100 / 122)$ & $72 \%(146 / 203)$ & Not performed & Not performed \\
Angina/MI ** & $86 \%(18 / 21)$ & $56 \%(5 / 9)$ & $1.6(0.9-2.9)$ & $1.7(.95-3.1)$ \\
No Angina/MI & $82 \%(98 / 120)$ & $73 \%(147 / 201)$ & $1.8(1.1-3.0)$ & $1.9(1.1-3.3)$ \\
Overall & $82 \%(116 / 141)$ & $72 \%(152 / 210)$ &
\end{tabular}

\footnotetext{
* Each variable adjusted for age, race, smoking, hypertension, and diabetes (less the stratified variable). Overall model and Angina/MI adjusted for age, race, smoking, hypertension, and diabetes. Including Angina/MI in adjusted overall model demonstrated no change in association (OR $=1.995 \%$ $\mathrm{Cl}=\mathrm{I} . \mathrm{I}-3.3)$.

** Insufficient sample size to perform diabetic or angina/MI analyses.

$\wedge$ The combined $A V$ and $V V$ genotypes within each strata serve as the reference group in all analyses, with the crude OR and adjusted $O R$ assigned a reference value of 1.0 .
}

Table 4: Etiologies among cases with a probable or possible cause of stroke

\begin{tabular}{|c|c|c|}
\hline & Probable Causes' $(n=70)$ & Possible Causes ${ }^{2}(n=30)$ \\
\hline Large-artery autherosclerosis & 9 & 8 \\
\hline Cardioembolism* & 16 & 14 \\
\hline Lacune & 7 & 3 \\
\hline Other determined cause ${ }^{* *}$ & 38 & 5 \\
\hline \multicolumn{3}{|c|}{$\begin{array}{l}\text { I One patient had } 2 \text { probable causes, but only I cause is listed according to the following hierarchy: large-artery atherosclerosis }>\text { cardioembolism } \\
>\text { lacune }>\text { other determined cause. } \\
2 \text { Most patients had multiple possible causes, but only I cause is listed per patient according to the same hierarchy as for probable causes. } \\
\text { * Note one probable case attributed to "other determined cause", also had possible cardioembolism as an etiology, this case was removed from the } \\
\text { secondary analysis. A total of } 31 \text { cases were removed from the secondary analysis on the basis of either probable }(n=16) \text { or possible }(n=15) \\
\text { cardioembolism as the stroke etiology. } \\
\text { ** Other determined causes included: Probable }=38,(10 \text { non-atherosclerotic vasculopathy, } 13 \text { hematologic, } 4 \text { migraine, } 6 \text { oral contraceptive or } \\
\text { exogenous estrogen use, } 5 \text { other drug related). Possible }=5,(3 \text { hematologic, } 2 \text { migraine). }\end{array}$} \\
\hline
\end{tabular}

demonstrated with the removal of all probable or possible cardioembolic strokes, a finding consistent with a recent meta-analysis demonstrating that cardioembolic stroke appears to have a smaller familial (or genetic) component that other subtypes of ischemic stroke [12]. Vascular risk factors were not significantly associated with specific genotypes in either analysis.

Several recent studies evaluating the THBD Ala455Val polymorphism and coronary artery disease (CAD) have yielded conflicting results. A Swedish case-control study found the alanine allele was associated with CAD [9]. In contrast, the American prospective ARIC study found the valine allele (AV plus $\mathrm{VV}$ ) was associated with an increase in CAD risk in both blacks (OR 4.4, 95\% CI 1.5-12.9) and whites (OR 1.4, 95\% CI 0.9-2.1), although the association attained statistical significance only in blacks [10]. A British case-control study found no association at all between the THBD Ala455Val polymorphism and CAD [17]. Consistent with the Swedish results [9], we observed an association between the alanine allele at this locus and stroke onset at a young age. It is unclear whether the conflicting information regarding the THBD Ala455Val polymorphism, ours included, is due to population-stratification bias, a functionally neutral polymorphism that serves as a marker for a nearby functional 
mutation (linkage disequilibrium), or the true existence of different associations in the different study populations.

Population-stratification bias is due to confounding by population admixture [18]. An unidentified subpopulation can confound the association between a genotype and disease if the subpopulation is associated with the genotype under study and the risk of disease. Because our results indicate that blacks have a higher prevalence of the AA genotype and have an increased risk of early-onset stroke, the AA genotype might be a marker for African ancestry in general rather than a marker for increased stroke susceptibility.

The THBD Ala455Val locus may be in linkage disequilibrium with an unobserved "high-risk" susceptibility locus. Linkage disequilibrium is a function of the history of the population, and thus true associations can occur in one population and not another.

Our results are also consistent with a causal association between stroke and the THBD Ala455Val polymorphism, thereby defining a susceptibility locus for the disease. An important criterion for a true susceptibility locus is that the polymorphism is associated with a change in protein expression or function. The THBD Ala455Val polymorphism has not been associated with variation in soluble thrombomodulin concentrations [19], but soluble thrombomodulin levels do not necessarily indicate the functional status of thrombomodulin on the endothelial surface. The Ala455Val polymorphism resides within a critical region for thrombomodulin function, specifically within the sixth EGF region. Epidermal growth factor (EGF) regions 4, 5, and 6 within the thrombomodulin molecule (see Figure 1) appear to play critical roles in the activation of protein $\mathrm{C}$ by thrombin $[2,8,20,21]$. Furthermore, this contiguous EGF segment is the minimal functional fragment of the thrombomodulin cofactor that can switch the specificity of thrombin from a procoagulant to an anticoagulant enzyme $[21,22]$. Furthermore, two polymorphisms close to the Ala455Val polymorphism, Arg385Ser and Pro477Ser, have been shown to influence the expression and function of thrombomodulin in a tissue culture model [23].

\section{Conclusions}

Thrombomodulin has not previously been examined as a candidate gene for stroke susceptibility. We found that among women aged 15 to 44 years, the AA genotype is more prevalent among blacks than whites and is associated with increased risk of early-onset ischemic stroke. Removing strokes potentially related to cardioembolic phenomena increased this association. Further studies are needed to determine whether this association is due to population stratification, linkage to a nearby functional polymorphism, or variation in thrombomodulin expression or function.

\section{Competing interest}

The author(s) declare that they have no competing interests.

\section{Authors' contributions}

All authors certify that they participated in the conceptual design of this work, the analysis of the data, and the writing of the manuscript to take public responsibility for it. All authors reviewed the final version of the manuscript and approve it for publication. J.W.C., S.J.K., B.D.M., M.A.W. and R.F.M. participated in the writing of the initial draft. M.G., K.K.S., W.H.G. and S.C.R. participated in the genotyping. J.W.C., S.J.K., B.D.M., and L.J.R. participated in the data analysis. All authors provided critiques of the final manuscript.

\section{Funding acknowledgments}

Dr. Cole's effort on this project was supported in part by an American Academy of Neurology Clinical Research Training Fellowship, by the National Institutes of Health Research Training in the Epidemiology of Aging (Grant T32-AG00262-04), and by the Department of Veterans Affairs, Baltimore, Office of Research and Development, Medical Research Service, and Stroke Research Enhancement Award Program. Dr. Kittner was supported in part by the Department of Veterans Affairs, Baltimore, Office of Research and Development, Medical Research Service, Geriatrics Research, Education and Clinical Center, and Stroke Research Enhancement Award Program; a Cooperative Agreement with the Division of Adult and Community Health, Centers for Disease Control and Prevention; the National Institute of Neurological Disorders and Stroke and the NIH Office of Research on Women's Health; the National Institute on Aging Pepper Center Grant P60 12583; and the University of Maryland General Clinical Research Center (Grant M01 RR 165001), General Clinical Research Centers Program, National Center for Research Resources, NIH.

\section{Acknowledgments}

We are indebted to the following members of the Stroke Prevention in Young Women research team for their dedication: Anne Epstein, Barbara Feeser, James Gardner, Mary Keiser, Ann Maher, Jennifer Rohr, Mary J.

Seipp, Susan Snyder, Mary J. Sparks, and Nancy Zappala.

The authors would like to acknowledge the assistance of the following individuals who have sponsored the Stroke Prevention in Young Women Study at their institution: Frank Anderson, MD; Clifford Andrew, MD, PhD; Christopher Bever, MD; Nicholas Buendia, MD; Young Ja Cho, MD; James Christensen, MD; Remzi Demir, MD; Terry Detrich, MD; John Eckholdt, MD; Nirmala Fernback, MD; Jerold Fleishman, MD; Benjamin Frishberg, MD; Stuart Goodman, MD, PhD; Norman Hershkowitz, MD, PhD; Luke Kao, MD, PhD; Mehrullah Khan, MD; Ramesh Khurana, MD; John Kurtzke, 
MD; William Leahy, MD; William Lightfoote II, MD; Bruce Lobar, MD; Micheal Miller, MD, PhD; Harshad Mody, MBBS; Marvin Mordes, MD; Seth Morgan, MD; Howard Moses, MD; Sivarama Nandipati, MD; Mark Ozer, MD; Roger Packer, MD; Thaddeus Pula, MD; Phillip Pulaski, MD; Naghbushan Rao, MD; Marc Raphaelson, MD; Solomon Robbins, MD; David Satinsky, MD; Elijah Saunders, MD; Micheal Sellman, MD, PhD; Arthur Siebens, MD (Deceased); Harold Stevens, MD, PhD; Dean Tippett, MD; Roger Weir, MD; Micheal Weinrich, MD; Richard Weisman, MD; Don Wood, MD (Deceased); and Mohammed Yaseen, MD.

In addition, the study could not have been completed without the support from the administration and medical records staff at the following institutions: In Maryland, Anne Arundel Medical Center, Atlantic General Hospital, Bon Secours Hospital, Calvert Memorial Hospital, Carroll County General, Church Hospital Corporation, Department of Veterans Affairs Medical Center in Baltimore, Doctors Community Hospital, Fallston General Hospital, Franklin Square Hospital Center, Frederick Memorial Hospital, The Good Samaritan Hospital of Maryland, Inc., Greater Baltimore Medical Center, Harbor Hospital Center, Hartford Memorial Hospital, Holy Cross Hospital, Johns Hopkins Bayview, Inc., The Johns Hopkins Hospital, Howard County General Hospital, Inc. Kennedy Krieger Institute, Kent and Queen Anne Hospital, Laurel Regional Hospital, Liberty Medical Center, Inc., Maryland General Hospital, McCready Memorial Hospital, Memorial Hospital at Easton, Mercy Medical Center, Montebello Rehabilitation Hospital, Montgomery General Hospital, North Arundel Hospital, Northwest Hospital Center, Peninsula Regional Medical Center, Physician's Memorial Hospital, Prince George's Hospital Center, Saint Agnes Hospital, Saint Joseph Hospital, Saint Mary's Hospital, Shady Grove Adventist Hospital, Sinai Hospital of Baltimore, Southern Maryland Hospital Center, Suburban Hospital, The Union Memorial Hospital, Union Hospital, University of Maryland Medical System, Washington Adventist Hospital and Washington County.

\section{References}

I. Esmon CT, Owen WG: Identification of an endothelial cell cofactor for thrombin-catalyzed activation of Protein C. Proc Natl Acad Sci USA I98I, 78:2249-52.

2. Esmon CT: Thrombomodulin as a model of molecular mechanism that modulates protease specificity and function at the vessel surface. FASEB J 1995, 9:946-55.

3. Esmon $\mathrm{CT}$ : The regulation of natural anticoagulant pathways. Science 1987, 235(4794): 1348-52.

4. Barnes PJ, Karin M: Nuclear factor-kappa b: a pivotal transcription factor in chronic inflammatory disease. N EnglJ Med 1997 , 336: 1066-7|.

5. Esmon CT: Role of coagulation inhibitors in inflammation. Thromb Haemost 200I, 86(I):51-6.

6. Ireland H, Kyriakoulis K, Kunz G, Lane DA: Directed search for thrombomodulin gene mutations. Haemostasis 1996, 26(Suppl 4):227-32.

7. van der Velden PA, Krommenhoek-Van Es T, Allaart CF, Bertina RM, Reitsma PH: A frequent thrombomodulin amino acid dimorphism is not associated with thrombophilia. Thromb Haemost 199I, 65(5):5। I-3.

8. Sadler JE: Thrombomodulin structure and function. Thromb Haemost 1997, 78(I):392-5.

9. Norlund L, Holm J, Zoller B, Ohlin AK: A common thrombomodulin amino acid dimorphism is associated with myocardial infarction. Thromb Haemost 1997, 77:248-5I.

10. Wu KK, Aleksic N, Ahn C, Boerwinkle E, Folsom AR, Juneja $\mathrm{H}$ : Atherosclerosis Risk in Communities Study (ARIC) Investigators. Thrombomodulin Ala455Val polymorphism and risk of coronary heart disease. Circulation 200I, I03:1386-9.

II. Kittner SJ, Stern BJ, Wozniak M, Buchholz DW, Earley CJ, Feeser BR, Johnson CJ, Macko RF, McCarter RJ, Price TR, Sherwin R, Sloan MA, Wityk RJ: Cerebral infarction in young adults: the BaltimoreWashington Cooperative Young Stroke Study. Neurology 1998, 50:890-4.
12. Schulz UGR, Flossmann E, Rothwell PM: Heritability of ischemic stroke in relation to age, vascular risk factors, and subtypes of incident stroke in population-based studies. Stroke 2004, 35:819-824.

13. Johnson CJ, Kittner SJ, McCarter RJ, Sloan MA, Stern BJ, Buchholz D, Price TR: Interrater reliability of an etiologic classification of ischemic stroke. Stroke 1995, 26:46-5I.

14. Kittner SJ, Stern BJ, Feeser BR, Hebel R, Nagey DA, Buchholz DW, Earley CJ, Johnson CJ, Macko RF, Sloan MA, Wityk RJ, Wozniak MA: Pregnancy and the risk of stroke. N Engl J Med 1996, 335:768-774.

15. Fakhrai-Rad H, Pourmand N, Ronaghi M: Pyrosequencing ${ }^{\mathrm{TM}}$ : an accurate detection platform for single nucleotide polymorphisms. Hum Mutat 2002, 19:479-485.

16. Nordfors L, Jansson M, Sandberg G, Lavebratt C, Sengul S, Schalling $M$, Arner P: Large-scale genotyping of single nucleotide polymorphisms by Pyrosequencing and validation against the 50 nuclease (TaqMan) assay. Hum Mutat 2002, 19:395-40I.

17. Ireland H, Kunz G, Kyriakoulis K, Stubbs PJ, Lane DA: Thrombomodulin gene mutations associated with myocardial infarction. Circulation 1997, 96:15-8.

18. Thomas DC, Witte JS: Point: population stratification: a problem for case-control studies of candidate-gene associations? Cancer Epidemiol Biomarkers Prev 2002, I I (6):505-12.

19. Aleksic N, Folsom AR, Cushman M, Heckbert SR, Tsai MY, Wu KK: Prospective study of the A455V polymorphism in the thrombomodulin gene, plasma thrombomodulin, and incidence venous thromboemolism: the LITE Study. J Thromb Haemost 2003, I ( I):88-94.

20. Yang L, Manithody C, Walston TD, Cooper ST, Rezaie AR: Thrombomodulin enhances the reactivity of thrombin with protein $C$ inhibitor by providing both a binding-site for the serpin and allosterically modulating the activity of thrombin. J Biol Chem 2003, 278(39):37465-70.

21. Esmon CT: Molecular events that control the protein $\mathbf{C}$ anticoagulant pathway. Thromb Haemost 1993, 70(I):29-35.

22. Kurosawa S, Stearns DJ, Jackson KW, Esmon CT: A 1 0-kDa cyanogen bromide fragment from the epidermal growth factor homology domain of rabbit thrombomodulin contains the primary thrombin-binding site. J Biol Chem 1988, 263(13):5993-6.

23. Kunz G, Ohlin AK, Adami A, Zoller B, Svensson P, Lane DA: Naturally occurring mutations in the thrombomodulin gene leading to impaired expression and function. Blood 2002, 99(10):3646-53.

\section{Pre-publication history}

The pre-publication history for this paper can be accessed here:

http://www.biomedcentral.com/1471-2377/4/21/prepub

Publish with Bio Med Central and every scientist can read your work free of charge

"BioMed Central will be the most significant development for disseminating the results of biomedical research in our lifetime. "

Sir Paul Nurse, Cancer Research UK

Your research papers will be:

- available free of charge to the entire biomedical community

- peer reviewed and published immediately upon acceptance

- cited in PubMed and archived on PubMed Central

- yours - you keep the copyright

Submit your manuscript here:

http://www.biomedcentral.com/info/publishing_adv.asp
BiolMedcentral 